\title{
Measuring $\beta$-diversity using a taxonomic similarity index, and its relation to spatial scale
}

\author{
C. Izsak, A. R. G. Price* \\ Ecology and Epidemiology Group, Department of Biological Sciences, University of Warwick, Coventry CV4 7AL, \\ United Kingdom
}

\begin{abstract}
We present a new similarity index, taxonomic similarity $\left(\Delta_{\mathrm{S}}\right)$, which can be used to measure $\beta$-diversity. $\Delta_{\mathrm{S}}$ utilises species presence/absence data, and incorporates both higher taxon richness and evenness concepts. It is derived from the average taxonomic distance (relatedness) of any 2 species from different sites. Therefore $\Delta_{\mathrm{S}}$ is analogous to taxonomic distinctness recently developed for biodiversity assessment at $\alpha$ - and $\gamma$ - (landscape or seascape) scales. $\Delta_{S}$ is a new index, although its derivation uses a concept similar to the 'optimal taxonomic mapping statistic' developed independently for quantifying structural redundancy in marine macrobenthos. Using echinoderm data, we show that $\Delta_{\mathrm{S}}$ exhibits smoother behaviour and is less influenced by species richness, and hence sampling effort, than the widely used Jaccard coefficient of species similarity. We also believe $\Delta_{\mathrm{S}}$ to be a more intuitive and comprehensive measure of similarity than Jaccard and other conventional indices based solely on species held in common. Taxonomic similarity between sites is computed for echinoderms examined over 3 different spatial scales: local/small-scale $(<10 \mathrm{~km})$, intermediate-scale $(10$ to $100 \mathrm{~s} \mathrm{~km})$ and province/oceanic-scale $(100 \mathrm{~s}$ to $1000 \mathrm{~s} \mathrm{~km})$. Taxonomic similarity between sites increases progressively with spatial scale, with significantly lower values and higher $\beta$-diversity at small spatial scales. The same pattern is evident for species similarity, using the Jaccard coefficient. Possible explanations for this pattern centre on: (1) the large-scale oceanic area examined (Indo-West Pacific), representing a metapopulation of echinoderms for the 2 other, smaller areas examined within (Pula Wé, Sumatra and Lakshadweeps); (2) greater biophysical instability and unpredictability at small spatial scales. Compared with larger spatial scales, these may be characterised by greater likelihood and influence of species migrations and extinctions on a site's total species composition. Hence, species composition may be highly changeable at small scales, leading to high $\beta$-diversity. These findings are based on 1 set of comparative data for 1 faunal group. Any wider conclusions drawn would be premature, although corals may also show greater $\beta$-diversity at small spatial scales. The extent to which patterns observed are evident for other marine species groups is not well known.
\end{abstract}

KEY WORDS: Biodiversity $\cdot \beta$-diversity $\cdot$ Taxonomic similarity $\cdot$ Echinoderms $\cdot$ Indo-West Pacific

\section{INTRODUCTION}

The utility of biodiversity measures which incorporate higher taxon richness and evenness is becoming increasingly recognised (review in Clarke \& Warwick 1999). Recently developed measures satisfying both requirements include taxonomic diversity $(\Delta)$ computed

*Corresponding author. E-mail: andrew.price@warwick.ac.uk from species abundance data, and taxonomic distinctness $\left(\Delta^{*}\right)$ determined from species (presence/absence) records, or 'quantitative' data such as biomass, prevalence or \% cover, rather than counts of individuals (Warwick \& Clarke 1995, Price et al. 1999). Taxonomic diversity/distinctness, being an average measure (of the relatedness between any 2 individuals/species in a community sample), is relatively insensitive to disparities in sampling effort (Clarke \& Warwick 1998a) and taxonomic rigour (Warwick \& Clarke 1998). Apart from

(C) Inter-Research 2001 
Simpson's diversity index (Lande 1996), most conventional measures of diversity (e.g. Shannon-Wiener, Pielou, Margalev) are based heavily on sample size. Additionally, taxonomic diversity/distinctness may have useful application in environmental monitoring and assessment (Warwick \& Clarke 1995, 1998), although this has not been confirmed in all subsequent studies (review in Clarke \& Warwick 1999).

Taxonomic diversity/distinctness measures biodiversity at $\alpha$ - (within-habitat) and $\gamma$ - (within-region) scales, the latter also termed 'landscape' or 'seascape' diversity (Gray 1997) and including large ocean provinces (Price et al. 1999). Another aspect of biodiversity is $\beta$-diversity, an area much neglected in the marine environment (Gray 2000). This is an estimate of spatial turnover of species along a gradient (e.g. from site to site). Methods for assessing $\beta$-diversity have involved measuring changes in species composition along a gradient (Whittaker 1960, 1975, Wilson \& Shmida 1984, Gray 2000), with recent modifications for transects of unequal size (Harrison et al. 1992), and also changes in values of a species similarity index (Gray 2000).

In this paper we define a similarity index, taxonomic similarity $\left(\Delta_{\mathrm{S}}\right)$, using a similar idea to that of $\Delta\left(\right.$ and $\left.\Delta^{*}\right)$, through consideration of taxonomic relatedness. This is a new index, although its derivation uses a similar concept to the 'optimal taxonomic mapping statistic' developed independently by Clarke \& Warwick (1998b) for quantifying structural redundancy in marine macrobenthos. We use our index, $\Delta_{\mathrm{S}}$, which utilises species presence/absence data, as a measure of $\beta$-diversity. We argue that $\Delta_{\mathrm{S}}$ may have advantages over conventional similarity indices, which utilise only data at the species level, since higher taxonomic levels (genera, families, orders etc.) in $\Delta_{\mathrm{S}}$ are taken into account in comparisons between sites/areas. We also examine some theoretical and empirical properties of $\Delta_{\mathrm{S}}$ and present analyses of several echinoderm datasets sampled over different spatial scales. For comparison, the behaviour of $\Delta_{\mathrm{S}}$ is assessed against the Jaccard coefficient, perhaps the most commonly used species similarity measure.

\section{METHODS}

Definition of taxonomic similarity. $\Delta_{\mathrm{S}}$ is a similarity index derived from taxonomic distance (TD) which is computed from species presence/absence data. TD is the average minimum path length between any 2 species in different sites/areas. We use path length in the same way as Warwick \& Clarke (1995), i.e. the relative taxonomic distance between any 2 species. If the species are classified into genera, families, orders, etc., the taxonomic path lengths are 0 (same species), 1 (different species but same genus), 2 (different genus but same family), 3 (different family but same order), etc. However, path length here refers to species in different sites/areas, rather than in only one site/area. $\Delta_{\mathrm{S}}$ is computed in 2 steps as follows:

(1) Given 2 sites, A and B, we define the TD between Sites A and B as follows:

$$
\mathrm{TD}=\frac{\sum_{i} w_{i B}+\sum_{j} w_{j A}}{n_{A}+n_{B}}
$$

where $W_{i B}$ is the minimum path length between Species $i$ at Site A and all species at Site $B_{i} w_{j A}$ is the minimum path length between Species $j$ at Site B and all species at Site $A_{i}$ and $n_{A}$ and $n_{B}$ are the number of species at Sites A and B respectively. Note that $\sum_{i} w_{i B}$ and $\sum_{j} W_{j A}$ are not necessarily equal (see Fig. 1). TD

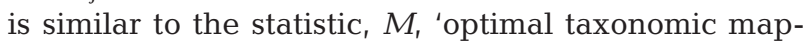
ping statistic' (Clarke \& Warwick 1998b), which uses an unweighted, rather than weighted, average path length.

(2) $\Delta_{S}$ is defined as:

$$
\Delta_{\mathrm{S}}=1-\frac{\mathrm{TD}}{L-1}
$$

where $L$ is the number of taxonomic levels used to classify the species (e.g. if the species have been classified into genus, family, order, class and phylum, $L=$ 6). $L-1$ can also be thought of as the maximum path length between a pair as species. Note that 1 minus the quotient of TD and $L-1$ makes $\Delta_{\mathrm{S}}$ satisfy the property of a similarity measure having values between 0 and 1. An example of how $\Delta_{\mathrm{S}}$ is computed for 2 sites, $A$ and $B$, is shown diagramatically in Fig. 1. In this example, these sites contain 6 and 7 species respectively, classified into genera, families and orders and here all assumed to belong to the same class. We have used constant incremental path lengths $(0,1,2$, etc.) in this example and thoughout this study, following the robustness of relative values of taxonomic distinctness to variation in the definition of path length (Clarke \& Warwick 1999).

Determination of $\boldsymbol{\beta}$-diversity from taxonomic similarity. As with conventional similarity indices (e.g. Sheppard 1985) a species similarity matrix is compiled of $\Delta_{\mathrm{S}}$ values for all pair-wise comparisons of species between 'sites'. Sites are here taken as the spatial units used for comparisons, irrespective of their area (Fig. 2). $\beta$-diversity is computed as the average (median) taxonomic similarity coefficient value in the similarity matrix. Since similarity matrix values are not independent of each other, it is not possible to perform statistical tests on the data to compare $\beta$-diversity between spatial scales and depths (see below). 
Site A Site B genus (1) family (2) order (3)



$$
\begin{aligned}
& \mathrm{TD}=\frac{\sum_{i} w_{i B}+\sum_{j} W_{j A}}{n_{A}+n_{B}} \\
& =\frac{(1+1+2+2+0+1)+(1+2+0+1+1+3+3)}{6+7}=\frac{18}{13} \\
& \Delta_{\mathrm{S}}=1-\frac{\mathrm{TD}}{L-1}=1-\frac{1.615}{4-1}=0.54
\end{aligned}
$$

Fig. 1. Illustration of how taxonomic similarity $\left(\Delta_{\mathrm{S}}\right)$ is computed for 2 different sites, A and B. Firstly, the minimum path length is determined between each species in Site A and all those at Site B, and then between each species in Site B and all those in Site A. Values for species at Site A are: 1 for Species 1, since it is absent from Site B but the genus is present at Site B (represented by Species 3), and similarly 1 for Species 2; 2 for Species 4, since the species and genus are absent from Site B but the family is present at Site B (represented by Species 3), etc. Conversely, the minimum path length for species at Site B is: 1 for Species 3, since it is absent from Site A but the genus is present at Site A (represented by Species 1 and 2), and 2 for Species 6, since the species and genus are absent from Site A but the family is present at Site A (represented by Species 7 and 9), etc. The path lengths (shown in bold above) correspond to the numbers in the first sum (Site A) and second sum (Site B) of the numerator. Secondly, the sum of all minimum path lengths are divided by the sum of the total number of species at each site to give TD, the taxonomic difference between Sites A and B. Thirdly, TD is divided by the total number of taxonomic levels minus 1 (i.e. maximum path length) to give a dissimilarity index, which is subtracted from 1 for conversion to the taxonomic similarity index, $\Delta_{\mathrm{S}}(0.54)$

Taxonomic similarity at different spatial scales and comparison with Jaccard similarity coefficient. Values of $\Delta_{\mathrm{S}}$ were computed for comprehensive shallowwater $(<30 \mathrm{~m}$ depth) echinoderm datasets for 3 geographical areas, increasing in scale from within-island, between-island up to province/ocean-scale (Table 1, Fig. 2). For comparison, values of Jaccard are also computed. The datasets are partly nested, since Pula Wé, Sumatra, and the Lakshadweeps lie within the IndoWest Pacific; but not fully nested (due to lack of suitable datasets), since Pula Wé, Sumatra, is not part of the Lakshadweeps island group.

Influence of sampling effort on taxonomic similarity. The influence of sampling effort on $\Delta_{\mathrm{S}}$ and Jaccard was determined by simulations using echinoderm presence/absence records from 3 randomly selected pairs of sites in (1) Pula Wé, Sumatra (above), and (2) the Atlantic from data used for the study of Price et al. (1999). For each pair-wise comparison of sites in each region, the full complement of species was listed, i.e. 'fixed', for the first site. Species found at the second site were then randomly selected and 'added', successively in increments of 1 species, so that species richness increased until the full species complement was reached. Values for the similarity coefficient were recomputed after addition of each successive species. Hence, the effect of species richness, and sampling effort, on our new $\Delta_{\mathrm{S}}$ index could be determined and

Table 1. Characteristics of the 3 regions of the Indo-West Pacific for which values of taxonomic similarity $\left(\Delta_{\mathrm{S}}\right)$ and Jaccard index were determined

\begin{tabular}{|llll|}
\hline Feature & Pula Wé, Sumatra & $\begin{array}{l}\text { Lakshadweeps, } \\
\text { or Laccadives }\end{array}$ & Indo-West Pacific \\
\hline $\begin{array}{l}\text { Area or region } \\
\begin{array}{l}\text { Proximity of 'sites' to each } \\
\text { other within region }\end{array}\end{array}$ & Small/within island & Intermediate/between island & Large/province (oceanic) \\
$\begin{array}{l}\text { No. of 'sites' within each } \\
\text { comparative region }\end{array}$ & 16 & $10 \mathrm{~s}-100 \mathrm{~km}$ & $100 \mathrm{~s}-1000 \mathrm{~s} \mathrm{~km}$ \\
$\begin{array}{l}\text { Source(s) for } \\
\text { echinoderm records }\end{array}$ & $\begin{array}{l}\text { Price \& Reid (1985), } \\
\text { Marsh \& Price (1991), } \\
\text { Price \& Rowe (1996), } \\
\text { Marshall-Crossland \& Price (1999) }\end{array}$ & 10 & 16 \\
& James (1989) & Clark \& Rowe (1971) \\
\hline
\end{tabular}




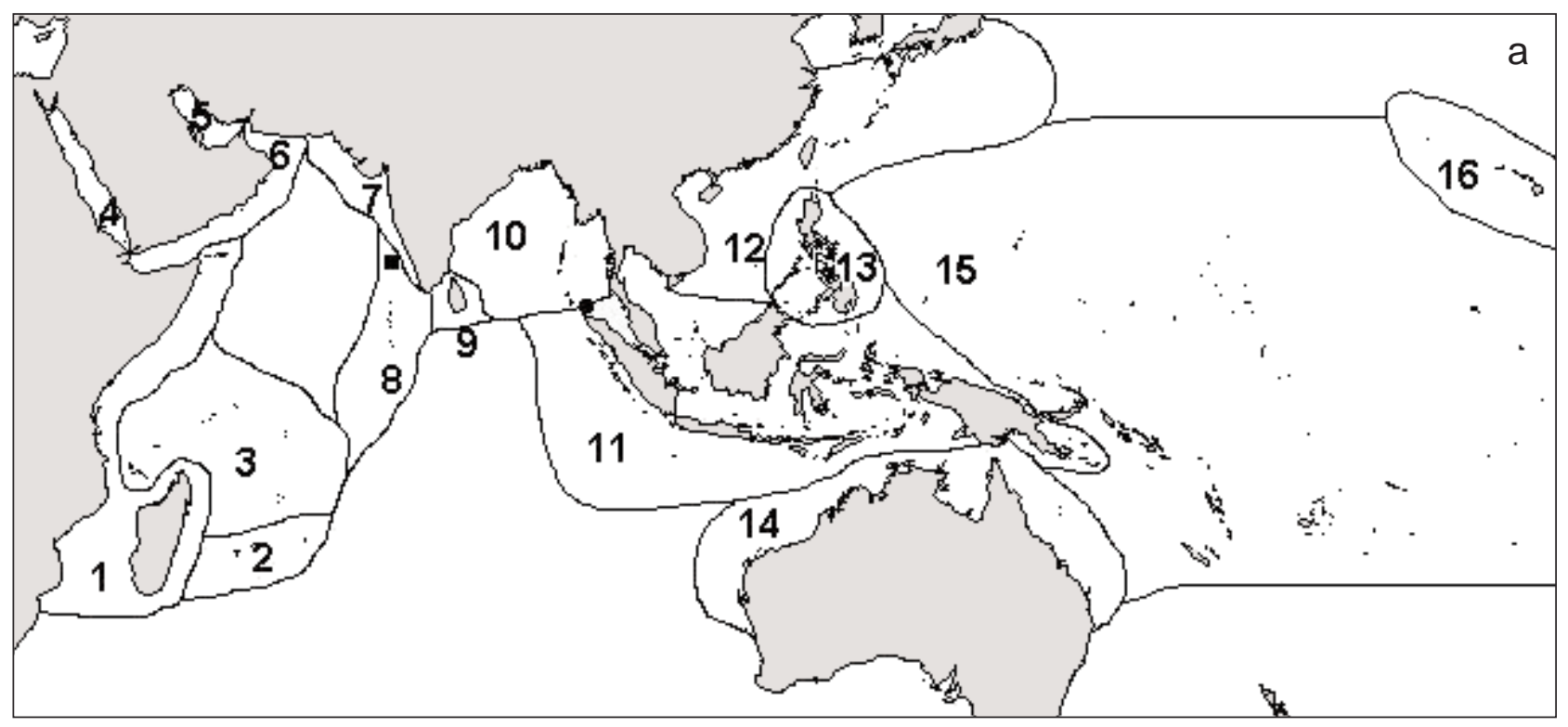

b

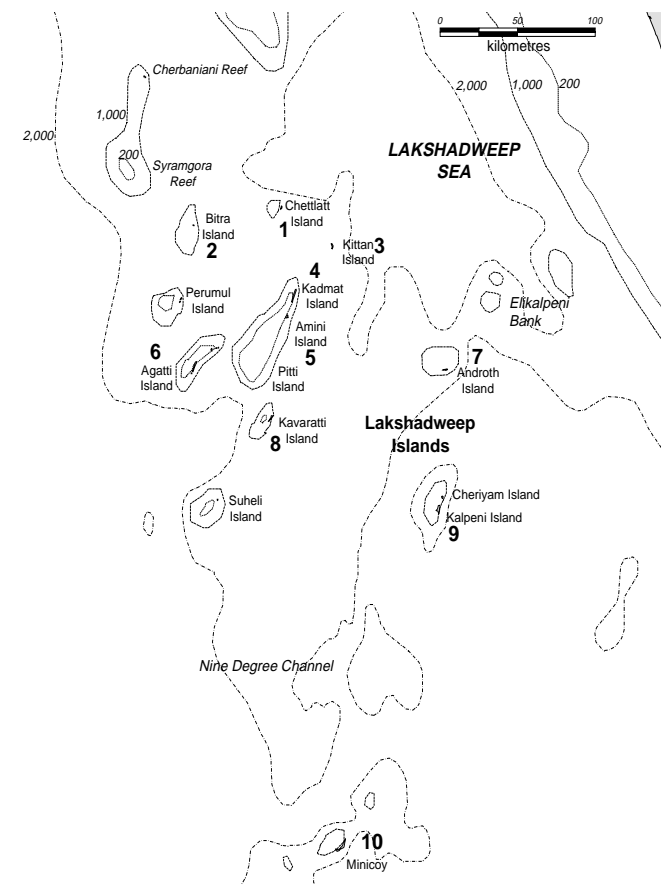

compared with the behaviour of a conventional similarity index (Jaccard). The same procedure was undertaken by 'fixing' the complement of the second site of a pair, then successively adding species from the first site.

Detecting depth differences in $\boldsymbol{\beta}$-diversity. We compare the ability of $\Delta \mathrm{s}$ and Jaccard to detect, qualitatively, differences in $\beta$-diversity between depth zones using the following species presence/absence datasets: (1) 3 different depth zones using echinoderm data for Pula Wé, Sumatra (above); (2) 3 different depth zones using Atlantic asteroid data (Price et al. 1999).
C
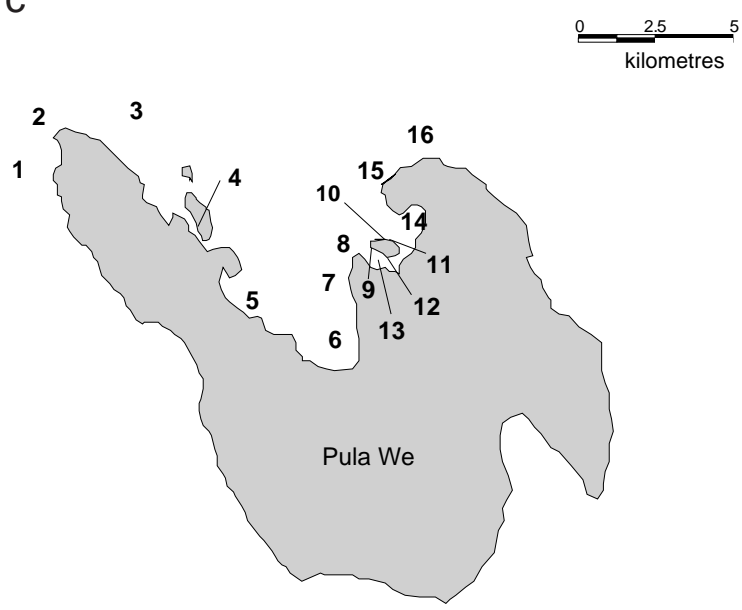

Fig. 2. Three regions of increasing spatial scale for which taxonomic similarity and Jaccard values were computed from echinoderm records (presence/absence) for (a) Indo-West Pacific (provinces or 'sites' as designated by Clark \& Rowe 1971), (b) Lakshadweeps or Laccadive islands ( $\bullet$ in 2a), (c) Pula Wé, Sumatra $(\bullet$ in 2a)

\section{RESULTS}

\section{Taxonomic similarity of echinoderms and comparison with Jaccard index}

Data on $\Delta_{\mathrm{S}}$ and Jaccard from echinoderm records (presence/absence data) are shown for 3 regions of increasing size and distance between each site within the Indo-West Pacific (Fig. 3, Table 2). A greater range is evident for values of $\Delta_{\mathrm{S}}(0.19$ to 0.9$)$ than Jaccard (0.03 to 0.58 ), and values of $\Delta_{\mathrm{S}}$ are also higher than Jaccard. This might be expected on account of the inclu- 


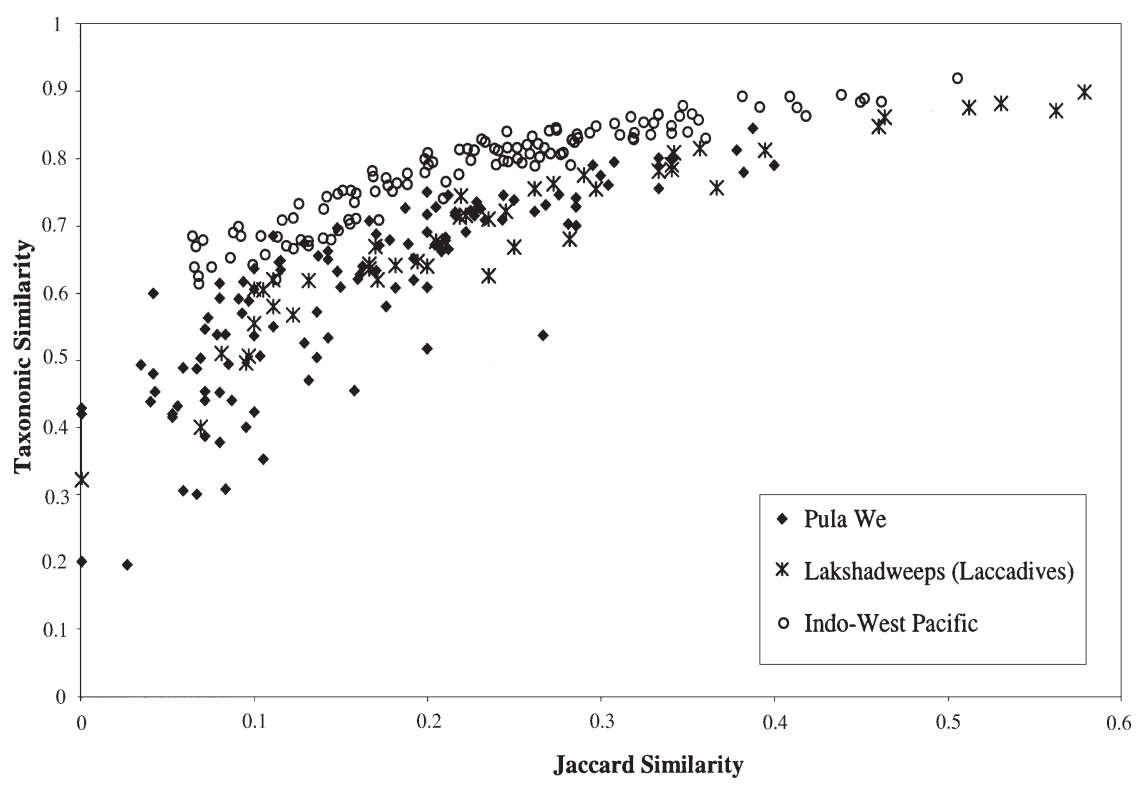

Fig. 3. Taxonomic similarity for 3 regions of increasing spatial scale for echinoderm records (presence/absence): Pula Wé, Sumatra, Lakshadweeps or Laccadive islands, and Indo-West Pacific. Jaccard values are shown for comparison

Table 2. Summary statistics for taxonomic similarity $\left(\Delta_{\mathrm{S}}\right)$ and Jaccard index using echinoderm (presence/absence) records from Pula Wé (Sumatra), Lakshadweeps and Indo-West Pacific

\begin{tabular}{|c|c|c|c|}
\hline & Pula Wé & Lakshadweeps & $\begin{array}{c}\text { Indo-West } \\
\text { Pacific }\end{array}$ \\
\hline \multicolumn{4}{|c|}{ Taxonomic similarity } \\
\hline Median & 0.635 & 0.680 & 0.798 \\
\hline Variance & 0.019 & 0.016 & 0.005 \\
\hline Range & 0.649 & 0.575 & 0.303 \\
\hline \multicolumn{4}{|c|}{ Jaccard index } \\
\hline Median & 0.159 & 0.222 & 0.233 \\
\hline Variance & 0.009 & 0.020 & 0.010 \\
\hline Range & 0.400 & 0.579 & 0.441 \\
\hline
\end{tabular}

Table 3. Summary statistics for taxonomic similarity $\left(\Delta_{\mathrm{S}}\right)$ and Jaccard index using echinoderm (presence/absence) records from 3 depth zones on coral reefs of Pula Wé, Sumatra. Shallow: 0 to $10 \mathrm{~m}$; medium: 11 to $20 \mathrm{~m}$; deep: $>20 \mathrm{~m}$

\begin{tabular}{|lccc|}
\hline & Shallow & Medium & Deep \\
\hline Taxonomic similarity & & & \\
$\quad$ Median & 0.491 & 0.434 & 0.570 \\
$\quad$ Variance & 0.025 & 0.034 & 0.008 \\
$\quad$ Range & 0.642 & 0.800 & 0.372 \\
Jaccard index & & & \\
$\quad$ Median & 0.093 & 0.071 & 0.077 \\
$\quad$ Variance & 0.008 & 0.007 & 0.005 \\
$\quad$ Range & 0.389 & 0.333 & 0.267 \\
\hline
\end{tabular}

sion of common taxa above species rank in computations of $\Delta_{\mathrm{S}}$. Jaccard and $\Delta_{\mathrm{S}}$ show strong correlation. Median similarity for both indices increases progressively from Pula Wé, Sumatra, to Lakshwadweeps, to the Indo-West Pacific. A reverse pattern is shown for the variance and range in values of $\Delta_{\mathrm{S}}$, whereas no consistent pattern in shown for the Jaccard index across scales. These results suggest greater species turnover (Jaccard data), greater taxonomic turnover $\left(\Delta_{\mathrm{S}}\right.$ data), and hence higher $\beta$-diversity, at small spatial scales than over larger scales.

\section{Sampling effort and taxonomic similarity}

The effect of increasing species richness on $\Delta_{\mathrm{S}}$ and the Jaccard coefficient is shown for selected echinoderm data from Pula Wé, Sumatra, in Fig. 4 and for asteroid data from the Atlantic in Fig. 5. The behaviour of $\Delta_{\mathrm{S}}$ with increasing species richness is generally smoother than that shown by the Jaccard index, which shows greater fluctuations (Fig. 4a). In addition, $\Delta_{\mathrm{S}}$ seems to approach an asymptote sooner than Jaccard (Fig. 4a). This suggests that $\Delta_{\mathrm{S}}$ is less influenced by species richness, and hence sampling effort, than Jaccard. In instances of very few species held in common, a steady decline in Jaccard is evident, whereas there will always be some commonality with $\Delta_{\mathrm{S}}$, whose behaviour is little different to that when many species are shared (Fig. 4b). A further point is that the lack of any shared species between 2 sites results in ' 0 ' similarity for Jaccard, whereas $\Delta_{\mathrm{S}}$ shows the same behaviour as when there are shared species (Fig. 5).

\section{Detecting depth differences in $\beta$-diversity}

Descriptive statistical data for Pula Wé, Sumatra, are shown in Table 3. Based on both $\Delta_{\mathrm{S}}$ and Jaccard, $\beta$ diversity is greatest in intermediate depths. Using $\Delta_{\mathrm{S}}$, $\beta$-diversity is greater for shallow than deep water, whereas the reverse pattern is evident using Jaccard. Data for the Atlantic are shown in Table 4. Here again, $\beta$-diversity is greatest for intermediate depths for both indices. Using $\Delta_{S}, \beta$-diversity is greater for deep than shallow water, whereas the reverse pattern is evident using Jaccard. 

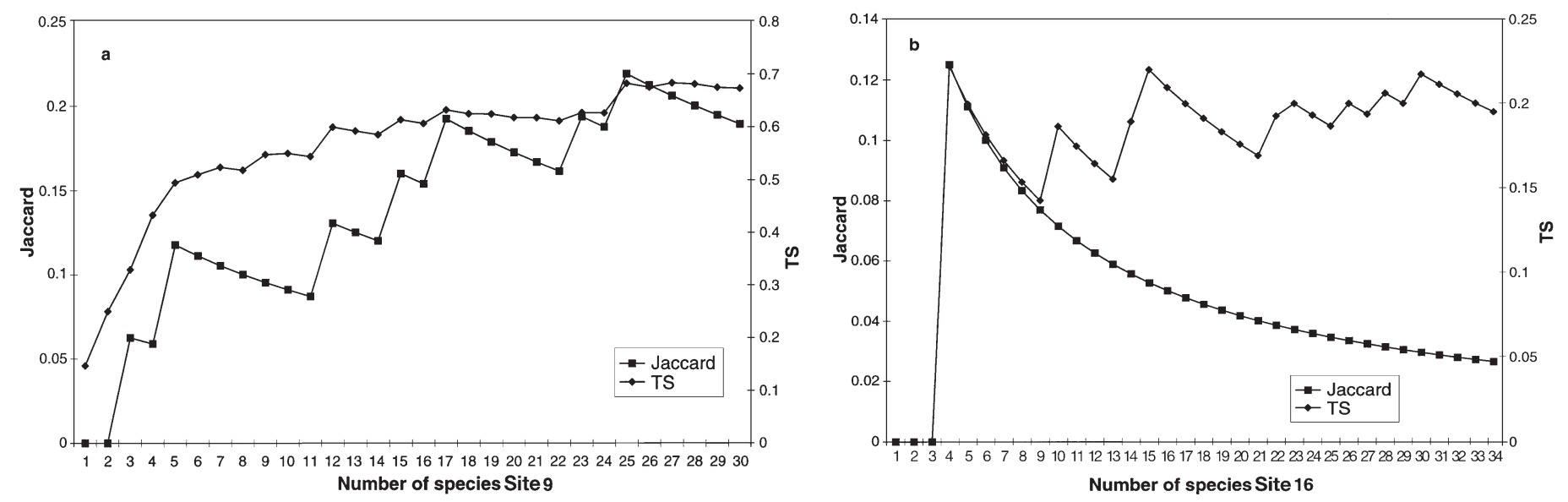

Fig. 4. Effect of increasing species richness, and hence sampling effort, on taxonomic similarity (TS) and the Jaccard index, based on pair-wise comparison of echinoderm records at sites in Pula Wé, Sumatra. (a) Species complement of Site 10 fixed with incremental additions of 1 species to Site 9; (b) species complement of Site 7 fixed with incremental additions of 1 species to Site 16 (see 'Methods' and Fig. 2c for site locations)

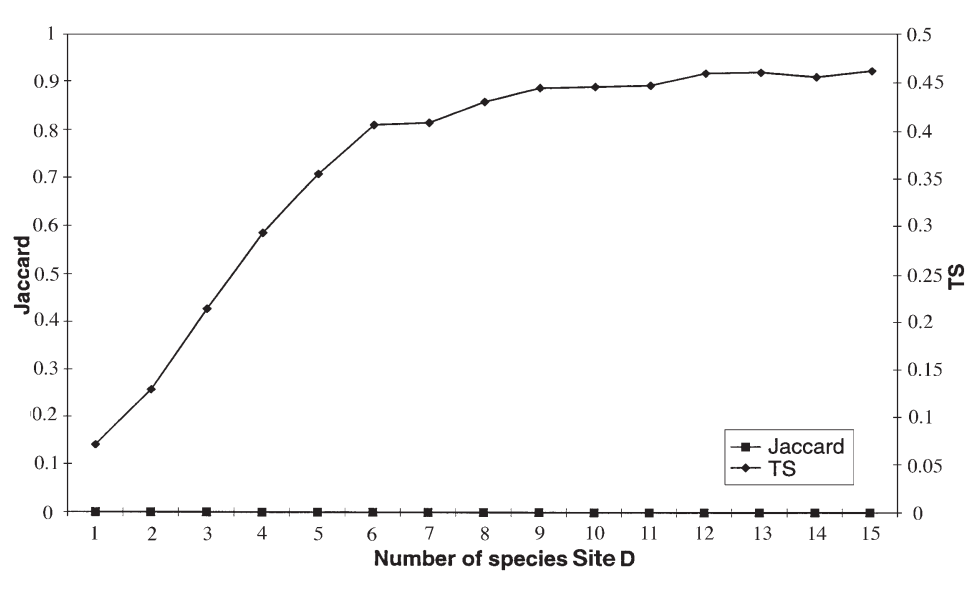

Fig. 5. Effect of increasing species richness, and hence sampling effort, on taxonomic similarity (TS) and the Jaccard index based on pair-wise comparison of asteroid records at sites in Atlantic. Species complement of Site N (South Angola to False Bay, South Africa) fixed with incremental additions of 1 species to Site D (Florida to Gulf of Mexico including Yukatan) (see 'Methods')

Table 4. Summary statistics for taxonomic similarity $\left(\Delta_{\mathrm{S}}\right)$ and Jaccard index using asteroid (presence/absence) records from 3 depth zones in Atlantic. Intertidal/shelf: 0 to $200 \mathrm{~m}$; upper bathyal: 200 to $500 \mathrm{~m}$; lower bathyal: >500 m

\begin{tabular}{|c|c|c|c|}
\hline & Intertidal & Upper bathyal & Lower bathyal \\
\hline \multicolumn{4}{|c|}{ Taxonomic similarity } \\
\hline Median & 0.560 & 0.338 & 0.454 \\
\hline Variance & 0.018 & 0.035 & 0.049 \\
\hline Range & 0.584 & 0.847 & 0.814 \\
\hline \multicolumn{4}{|c|}{ Jaccard index } \\
\hline Median & 0.049 & 0 & 0.106 \\
\hline Variance & 0.007 & 0.009 & 0.002 \\
\hline Range & 0.400 & 0.523 & 0.250 \\
\hline
\end{tabular}

\section{DISCUSSION}

Wilson \& Shmida (1984) highlight the importance of $\beta$-diversity in indicating the extent to which habitats have been partitioned by species, as a means of comparing habitat diversity and, together with $\alpha$-diversity, as a measure of overall biotic heterogeneity of an area. The importance of $\beta$-diversity for assessment of landscape diversity and, in turn, conservation value, has also been stressed recently (Tuomisto et al. 1995, Gray 1997). Compared with $\alpha$-diversity, however, knowledge of $\beta$-diversity in the marine context is more limited (Gray 2000). Some recent exceptions addressing $\beta$-diversity explicitly include studies on sponges (Carballo et al. 1996), bryozoans (Clarke \& Lidgard 1999), polychaetes (Paterson et al. 1998), asteroids (Price et al. 1999), ascidians (Naranjo et al. 1998), and associations between benthic habitats and $\beta$ diversity (Parry et al. 1999). Several authors have recently produced interesting plots of Bray-Curtis similarity against distance apart of the samples (Hull 1999, Kendall \& Widdecombe 1999). Experimental work has included assessment of associations between bioturbation/feeding and $\beta$-diversity (Widdicombe \& Austen 1998, 1999). Many other studies have examined species similarity (e.g. Price 1982, Sheppard \& Sheppard 1991), although generally only implicitly as a means of estimating $\beta$-diversity.

Based on our preliminary studies, $\Delta_{\mathrm{S}}$ appears to be less influenced by sampling effort than Jaccard. A likely reason is that $\Delta_{\mathrm{S}}$ is a measure of average taxonomic relatedness, unlike conventional measures that depend only on (shared) species. This is analagous to the contrast between taxonomic diversity/distinctness 
( $\Delta$ and $\Delta^{*}$; Warwick \& Clarke 1995, Clarke \& Warwick 1998a) and species richness. The optimal taxonomic mapping statistic, $M$ (Clarke \& Warwick 1998b), may be even less influenced by sample-size disparities.

Another possible practical advantage of $\Delta_{\mathrm{S}}$ over other similarity coefficients concerns taxonomic robustness. As shown for $\Delta$ and $\Delta^{*}$ (Clarke \& Warwick 1998a, Warwick \& Clarke 1998), disparities in taxonomic rigour (e.g. misidentifications) are generally less likely to influence values of $\Delta_{\mathrm{S}}$ than conventional similarity indices.

Moreover, we suggest that biodiversity measures are more comprehensive if based on all taxonomic levels, not just species. This is in closer accordance with the wider meaning and more recent definitions of biodiversity (e.g. Harper \& Hawksworth 1994, Gray 1997, Clarke \& Warwick 1998a): genetic (within-species), species and ecological (community/assemblage) diversity, particularly when species ('organismal' sensu Harper \& Hawksworth 1994) diversity is taken to embrace taxonomic categories above species rank. Information on genetic diversity is seldom available for use in ecological analysis, except sometimes as records of sub-species (Clark \& Rowe 1971, Price 1982, Clark \& Downey 1992). In principle, however, such data could be incorporated into computations of taxonomic similarity (and taxonomic distinctness) (Clarke \& Warwick 2001).

A dendrogram, or multidimensional scaling (MDS) plot, is commonly used to provide graphic representation of how species similarity changes along a gradient (e.g. between sites) in a particular area or environment. Longer branch lengths within a dendrogram denote relatively low similarity, and hence high $\beta$ diversity (e.g. Price et al. 1999). However, since quantitative comparison of dendrograms is difficult, we have used the species similarity matrix for computing and comparing similarity between sites. Comparisons of $\Delta_{\mathrm{S}}$ (or Jaccard) can thus be made more readily between different environments, habitats, depths and spatial scales.

Our finding of increasing taxonomic (and species) similarity level at larger spatial scales initially seemed contrary to the observed, and expected, significant inverse correlation between geographical distance and species similarity, for example in Indian Ocean corals (Sheppard 1998), Atlantic ascidians (Naranjo et al. 1998) and Atlantic asteroids (Price et al. 1999). However, these patterns of similarity are evident for a particular (large) scale, whereas in this study we are comparing similarity across scales (small/intermediate/ large-scale). The results also seem striking given that a wider range of habitats is represented for the largescale (Indo-West Pacific) dataset, yet is associated with lowest $\beta$-diversity. In contrast, only 1 major habitat (coral reef) is represented in the intermediate- (Lakshadweeps) and small-scale (Pula Wé, Sumatra) datasets, both of which are associated with higher $\beta$-diversity.

Assuming that the observed correlations between $\beta$-diversity and spatial scale are not due to chance (probability of ascending or descending rank order in 3 datasets is one-third), and that the availability of only partly nested datasets is not a major limitation, a possible explanation is the following. The Indo-West Pacific population may effectively be a metapopulation (Harrison 1994, 1998, May 1994) of echinoderms, with many species showing widespread distribution (Clark \& Rowe 1971, Devaney 1973, Clark 1984, Price \& Reid 1985). This reflects their relatively long larval duration (Devaney 1973) and excellent dispersal capability. Our study suggests that sites which are extensive in area and widely separated (Indo-West Pacific) are relatively homogeneous in terms of species composition. Any 'localised' species extinctions or migrations are probably unlikely to result in overall loss of that species from a site (i.e. area), due to its presence in other patches within the site. Hence, an overall high level of species similarity and $\Delta_{\mathrm{S}}$ (i.e. low $\beta$-diversity) might be expected, and is observed, at large spatial scales.

In contrast, at sites that are small in area and in close proximity to each other (Pula Wé, Sumatra), 'localised' species extinctions or migrations may often equate to total loss of a species from that site. This might arise from effects of predation, competition or other effects of patch dynamics, resulting in collapse of species when too few fragments of habitat remain (Harrison 1994). Related to this, self-organised (by species) spatial heterogeneity is also known to influence the persistence of species (May 1994), and may be more prevalent over smaller than larger scales in the present context. These factors, invoking instability and unpredictability at small spatial scales (May 1994), might partly explain the low levels of similarity and high $\beta$ diversity observed, and the reverse pattern at larger scales. These apparent scaling effects are highly significant for taxonomic similarity, and less so but still discernible using the Jaccard coefficient. Biogeographical factors should also not be overlooked, although their possible influence on $\beta$-diversity is not completely clear. Pula Wé, Sumatra, lies at the intersection of 2 different nominal biogeographic provinces (10 and 11 in Fig. 2), as does the Lakshadweeps (between 7 and 8 in Fig. 2), and both are characterised by higher $\beta$-diversity than the Indo-West Pacific. High $\beta$-diversity related to geographical boundaries/ecotones has been reported for ascidians (Naranjo et al. 1998). However, relatively high $\beta$-diversity is also apparent for corals in the Arabian Gulf (see below), which does not lie close to a biogeographical boundary (Clark \& Rowe 1971, 
Sherman 1994). The relative interplay between biogeography and spatial scaling effects (e.g. greater uncertainty/unpredictability at smaller scales) needs further assessment. Further, even the definition of marine biogeographic areas and the boundaries between them is still debatable, and depends on the underlying criteria used (Sherman 1994).

Our findings are based on 1 set of comparative data for 1 faunal group (echinoderms). Any wider conclusions drawn would therefore be premature. The extent to which the same spatial patterns are also shown by other marine species groups, and the scale(s) at which $\beta$-diversity is maximal, require further study. Corals may show a pattern similar to echinoderms, with greater similarity (and lower $\beta$-diversity) at larger than smaller spatial scales. This is based on preliminary comparison between the wider Indian Ocean (Sheppard 1987, his Fig. 2) and 2 smaller regions: the Red Sea (Sheppard \& Sheppard 1991, their Fig. 7) and the Bahrain coast of the Arabian Gulf (Sheppard 1988, his Fig. 1). The cluster analyses are all based on the same clustering method (group average). However, the similarity coefficient used is the same only for the first 2 regions (Dice coefficient), but different for the Gulf (Jaccard) - accentuating dissimilarity between sites. If the Dice coefficient is computed for the Gulf (data not shown), similarity between sites increases. While positive association between spatial scale and species similarity is discernible from qualitative comparison of the dendrograms, all based on Jaccard, comprehensive analysis of the data is needed for a clearer picture. The known interannual fluctuations and unpredicatability of coral species from studies of $1 \mathrm{~m}^{2}$ quadrats and coral fish species on small coral reefs (May 1994) would seem to support suggestions of greater $\beta$-diversity at small scales. For nematodes, which are small, relatively immobile and poor dispersers, positive association between spatial scale and species similarity may also occur. The scale at which dissimilarity and $\beta$ diversity are greatest for nematodes may be very small, possibly in the order of centimetres to metres (J. Lambshead pers. comm.).

It will also be useful to examine the utility of $\Delta_{\mathrm{S}}$ for environmental monitoring and assessing environmental change. It is possible that $\Delta_{\mathrm{S}}$ might have the benefits of a measure based heavily on average properties (like $\Delta / \Delta^{*}$, which in at least some studies has detected environmental degradation; Warwick \& Clarke 1995, 1998, Clarke \& Warwick 1999), and also carry the known advantages of multivariate techniques for detecting environmental impacts and community shifts (Clarke \& Warwick 1999).

Acknowledgements. We thank O. Langmead for assistance with computing, and G. Medley, D. Morse, J. Nokes, C. Shep- pard and C. Roberts for advice and discussions. For assistance with graphics we thank A. and C. Sheppard. We are also grateful for the helpful suggestions, comments and criticisms made by the referees.

\section{LITERATURE CITED}

Carballo JL, Naranjo SA, Garcia-Gomez JC (1996) Use of marine sponges as stress indicators in marine ecosystems at Algeciras Bay (southern Iberian Peninsula). Mar Ecol Prog Ser 135:109-122

Clark AM (1984) Echinodermata of the Seychelles. In: Stoddart DR (ed) Biogeography and ecology of the Seychelles Islands. Dr W Junk Publishers, The Hague, p 83-102

Clark AM, Downey ME (1992) Starfishes of the Atlantic. Natural History/Chapman \& Hall, London

Clark AM, Rowe FEW (1971) Monograph of shallow-water Indo-West Pacific echinoderms. British Museum (Natural History), London

Clarke A, Lidgard SM (1999) Spatial patterns of diversity in the sea: bryozoan species richness in the North Atlantic. J Anim Ecol 69:785-798

Clarke KR, Warwick RM (1998a) A taxonomic distinctness index and its statistical properties. J Appl Ecol 35:423-531

Clarke KR, Warwick RM (1998b) Quantifying structural redundancy in ecological communities. Oecologia 113: 278-289

Clarke KR, Warwick RM (1999) The taxonomic distinctness measure of biodiversity: weighting of step lengths between hierarchical levels. Mar Ecol Prog Ser 184:21-29

Clarke KR, Warwick RM (2001) A further biodiversity index applicable to species lists: variation in taxonomic distinctness. Mar Ecol Prog Ser (in press)

Devaney DM (1973) Zoogeography and faunal composition of south-western Polynesian asterozoan echinoderms. In: Fraser R (ed) Oceanography of the South Pacific 1972. New Zealand National Commission for UNESCO, Wellington, p 357-366

Gray JS (1997) Marine biodiversity: patterns, threats and conservation needs. Biodivers Conserv 6:153-175

Gray J (2000) The measurement of marine species diversity with an application to the benthic fauna of the Norwegian continental shelf. J Exp Mar Biol Ecol 250:23-49

Harper JL, Hawksworth DL (1994) Biodiversity: measurement and estimation. Philos Trans R Soc Lond Ser B 345:5-12

Harrison H (1998) Do taxa persist in evolutionary time? In: McKinney ML, Drake JA (eds) Biodiversity dynamics: turnover of populations, taxa and communities. Columbia University Press, New York

Harrison S (1994) Metapopulations and conservation. In: Edwards PJ, May RM, Webb NR (eds) Large-scale ecology and conservation biology. British Ecological Society/ Blackwell Scientific Publications, Oxford, p 111-128

Harrison S, Ross SJ, Lawton JH (1992) $\beta$ diversity on geographic gradients in Britain. J Anim Ecol 61:151-158

Hull SL (1999) Comparison of tidepool phytal ostracod abundance and assemblage structure on three spatial scales Mar Ecol Prog Ser 182:201-208

James DB (1989) Echinoderms of Lakshadweep and their zoogeography. Bull Cent Mar Fish Res Inst 43:97-144

Lande R (1996) Statistics and partitioning of species diversity, and similarity among multiple species communities. Oikos 76:5-13

Kendall MA, Widdicombe S (1999) Small scale patterns in the structure of macrofaunal assemblages of shallow soft sediments. J Exp Mar Biol Ecol 237:127-140 
Marsh LM, Price ARG (1991) Indian Ocean echinoderms collected during the Sindbad voyage (1980-81): 2. Asteroidea. Bull Br Mus (Nat Hist) Zool 57:61-70

Marshall-Crossland JI, Price ARG (1999) Indian Ocean echinoderms collected during the Sindbad Voyage (1980-81): 4. Crinoidea. Bull Br Mus (Nat Hist) Zool 65:23-29

May RM (1994) The effects of spatial scale on ecological questions and answers. In: Edwards PJ, May RM, Webb NR (eds) Large-scale ecology and conservation biology. British Ecological Society/Blackwell Scientific Publications, Oxford, p 1-17

Naranjo S, Carballo JL, Garcia-Gomez JC (1998) Towards a knowledge of marine boundaries using ascidians as indicators: characterising transition zones for species distribution along Atlantic-Mediterranean shores. Biol J Linn Soc 64:151-177

Parry DM, Kendall MA, Rowden AA, Widdicombe (1999) Species body size distribution patterns of marine benthic macrofauna assemblages from contrasting sediment types. J Mar Biol Assoc UK 79:793-801

Paterson GLJ, Wilson GDF, Cosson N, Lamont PA (1998) Hessler and Jumars (1974) revisited: abyssal polychaete assemblages from the Atlantic and Pacific. Deep-Sea Res 45:225-251

Price ARG (1982) Echinoderms of Saudi Arabia: comparison between echinoderm faunas of Arabian Gulf, SE Arabia, Red Sea and Gulfs of Aqaba and Suez. Fauna Saudia Arabia $4: 3-21$

Price ARG, Reid CE (1985) Indian Ocean echinoderms collected during the Sindbad voyage (1980-81): 1. Holothurioidea. Bull Br Mus (Nat Hist) Zool 48:1-9

Price ARG, Rowe FWE (1996) Indian Ocean echinoderms collected during the Sindbad Voyage (1980-81): 3. Ophiuroidea and Echinoidea. Bull Br Mus (Nat Hist) Zool 62: 71-82

Price ARG, Keeling MJ, O'Callaghan CJ (1999) Ocean-scale patterns of 'biodiversity' of Atlantic asteroids determined from taxonomic distinctness and other measures. Biol J Linn Soc 66:187-203

Sheppard CRC (1985) Reefs and coral assemblages of Saudi

Editorial responsibility: Kenneth Sherman (Contributing Editor), Narragansett, Rhode Island, USA
Arabia. 2. Fringing reefs in the southern region, Jeddah to Jizan. Fauna Saudia Arabia 7:37-58

Sheppard CRC (1987) Coral species of the Indian Ocean and adjacent seas: a synonymised compilation and some regional distributional patterns. Atoll Res Bull 307:1-32

Sheppard CRC (1988) Subtidal hard substrates. In: Vousden DHP (ed) The Bahrain marine habitat survey, Vol 1. The technical report. Regional organisation for protection of the marine environment (ROPME), Kuwait, p 38-49

Sheppard CRC (1998) Biodiversity patterns in Indian Ocean corals, and effects of taxonomic error in data. Biodivers Conserv 7:847-868

Sheppard CRC, Sheppard ALS (1991) Corals and coral communities of Arabia. Fauna Saudia Arabia 12:3-170

Sherman K (1994) Sustainability, biomass yields, and health of coastal ecosystems: an ecological perspective. Mar Ecol Prog Ser 112:277-301

Tuomisto H, Ruokolainen K, Kalliola R, Liina A, Danjoy W, Rodriguez Z (1995) Dissecting Amazonian biodiversity. Science 269:63-66

Warwick RM, Clarke KR (1995) New ‘biodiversity' index measures reveal a decrease in taxonomic distinctness with increasing stress. Mar Ecol Prog Ser 129:301-305

Warwick RM, Clarke KR (1998) Taxonomic distinctness and environmental assessment. J Appl Ecol 35:532-543

Whittaker RH (1960) Vegetation of the Siskiyou Mountains. Oregon and California. Ecol Monogr 30:279-338

Whittaker RH (1975) Communities and ecosystems, 2nd edn. Macmillan, London

Widdicombe S, Austen MC (1998) Experimental evidence for the role of Brissopsis lyrifera (Forbes, 1841) as a critical species in the maintenance of benthic diversity and the modification of sediment chemistry. J Exp Mar Biol Ecol 228:241-255

Widdicombe S, Austen MC (1999) Mesocosm investigation into the effects of bioturbation on the diversity and structure of a subtidal macrobenthic community. Mar Ecol Prog Ser 189:181-193

Wilson MV, Shmida A (1984) Measuring $\beta$ diversity with presence and absence data. J Ecol 72:1055-1064

Submitted: April 5, 2000; Accepted: July 27, 2000

Proofs received from author(s): March 26, 2001 